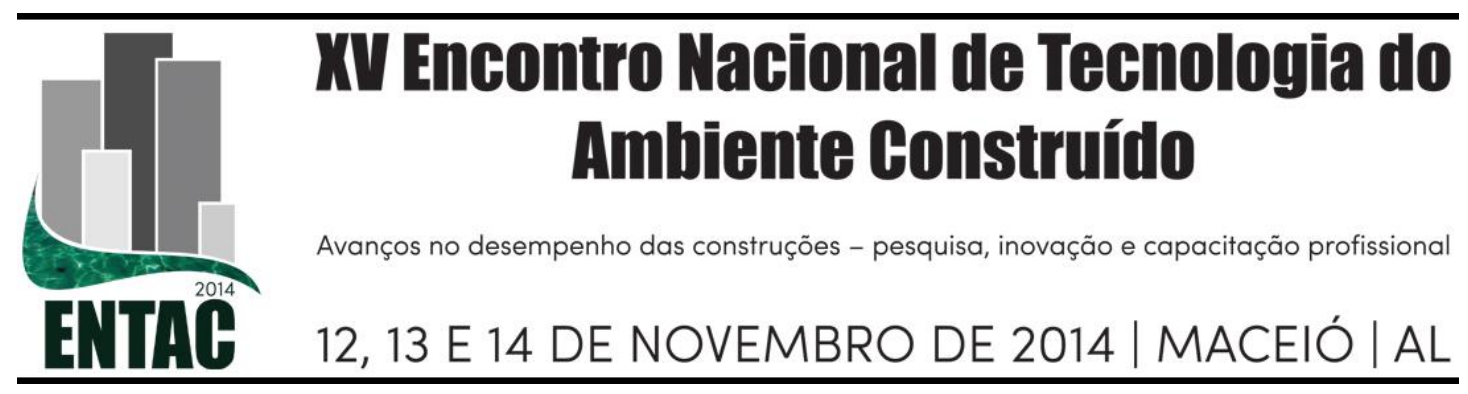

\title{
APLICAÇÃO DE ELEMENTOS DE INFRAESTRUTURA VERDE EM UMA MICRO-BACIA URBANA
}

\author{
SCARPINELLA, Gustavo D’Almeida (1); SILVA, Ricardo Siloto da (2); \\ OLIVEIRA, Simone Cristina de (3)
}

(1) Universidade Federal de São Carlos, e-mail: gscarpinella@ gmail.com (2) Universidade Federal de São Carlos, e-mail: rss@ufscar.br, (3) Universidade Federal de São Carlos, e-mail:

simonecoliv@gmail.com

\begin{abstract}
RESUMO
No presente artigo é relatada uma pesquisa desenvolvida com o objetivo de diagnosticar, identificar e caracterizar os elementos de infraestrutura verde passíveis de aplicação em áreas públicas, institucionais e de recreio, dentro de uma sub-bacia hidrográfica da área urbana do município de São Carlos/SP. A metodologia consistiu na pesquisa em literatura técnico-científica, além do levantamento de informações com a prefeitura local. Recorreu-se à aplicação de Sistema de Informações Geográficas (SIG), com emprego de imagens de satélite Quick Bird, datadas de 2008 e com resolução espacial de 0,60 m. Foi utilizado o software ArcGis 10.1. Como auxílio, foram tiradas fotografias in loco de cada trecho estudado, possibilitando uma visualização recente e mais detalhada de cada área. $\mathrm{O}$ artigo é apresentado com um enfoque exploratório e descritivo. O resultado da pesquisa apresenta como área de estudo a micro-bacia urbana do município de São Carlos (SP), conhecida como "Tijuco Preto" e dentro dela, as áreas públicas institucionais e de recreio. A bacia tem uma área de $2,6 \mathrm{~km}^{2}$, conta com 22 áreas públicas de recreio e 8 terrenos públicos institucionais. Dentre os elementos de infraestrutura verde que vêm sendo trabalhados na pesquisa foram propostos para análise de aplicação ou melhoria os seguintes elementos: desconexão de calhas, coleta de águas pluviais, jardins de chuva, biovaletas, pavimentos permeáveis, estacionamentos verdes, telhados verdes e arborização urbana. Os resultados apontam que todas as sub-áreas analisadas são passíveis de melhorias e adaptações que garantam maior qualidade ambiental. Este artigo apresenta, portanto, um diagnóstico que retrata como as áreas públicas destinadas a fins institucionais e de recreio vêm tendo suas superfícies livres cobertas/tratadas.
\end{abstract}

Palavras-chave: Infraestrutura verde, Micro-bacia, São Carlos.

\begin{abstract}
The aim of this research is to diagnose, identify and characterise green infrastructure elements subject to application in public, institutional and recreational areas in a hydrographic sub-basin in an urban area in the city of São Carlos (São Paulo state, Brazil). The methodology consisted of a technoscientific literature review, as well as collecting information from the local council. The Geographic Information System was used, as well as Quick Bird satellite imagery, dating back to 2008 and a spatial resolution of $0.60 \mathrm{~m}$. The ArcGis 10.1 software was also used. As an aid, in loco photographs were taken of each studied stretch, so that recent and more detailed images of each area could be obtained. The article has an exploratory and descriptive focus. The results of the research show the urban micro-basin in the city of São Carlos as an area of study, known as "Tijuco Preto" and in it, public, institutional and recreational areas. The basin has an area of $2.6 \mathrm{~km} 2,22$ public recreational areas and 8 public institutional pieces of land. Among the green infrastructure elements that were studied in the research, the following elements to analyse and improve were proposed: disconnecting pipes, collecting rainwater,
\end{abstract}


gutters, bioditches, permeable surfacing, green parking, green roofs and urban green areas. Results show that all the sub-areas analysed could be improved and adaptations made, which ensure better environmental quality. Therefore, this article presents a diagnosis, which shows how public areas have had their free surfaces covered/treated for institutional and recreational purposes.

Keywords: Green infrastructure, Micro-watersheds, São Carlos.

\section{INTRODUÇÃO}

As cidades são, em essência, o locus do ambiente construído. A adoção de ecotécnicas nos seus sistemas de drenagem, de água, esgoto, pavimento viário e outros sistemas, somada aos elementos vegetais urbanos, pode ser entendida como uma infraestrutura verde que, além de servir como conexão ecológica e da aproximação entre os recursos naturais e os construídos, contribui para o bem-estar ambiental dos seus cidadãos.

As áreas públicas de uma cidade exercem um importante papel por proporcionarem aos seus habitantes espaços de lazer e ócio, prestação de serviços e circulação entre bairros e regiões. Foram analisadas neste artigo as áreas públicas institucionais e áreas de recreio de uma micro-bacia hidrográfica da área urbana de São Carlos (SP). Áreas institucionais são aquelas destinadas "à instalação de edificações e/ou equipamentos públicos comunitários”. Já as áreas de recreio (ou lazer) são aquelas livres de "preservação ambiental destinadas à implantação de áreas para esportes, cultura e lazer, praças e parques” (São Carlos, 2005).

O conceito de infraestrutura verde traz em si o princípio da mimese da natureza através da adoção de ecotécnicas no espaço urbano. De acordo com a Environmental Protection Agency (2013) a infraestrutura verde aproveita as características hidrológicas naturais do meio para prover o gerenciamento da água e garantir ambientes urbanos mais saudáveis. A junção de técnicas pode proporcionar uma malha verde mais consistente e contínua, acompanhando corpos d'água, trechos urbanos de interesse social e cultural, além de um ambiente mais constituído das diversas formas de vida.

A tipologia formadora da infraestrutura verde pode ser destacada através das seguintes técnicas (ENVIRONMENTAL PROTECTION AGENCY, 2013):

- Desconexão de calhas - quando as calhas dos telhados são conduzidas a uma área permeável e próxima, ao invés de serem destinadas ao sistema de drenagem convencional; Coleta de águas pluviais - através do método de armazenamento das águas pluviais em cisternas; Jardins de chuva - caixas ajardinadas localizadas em cotas inferiores do local em que se encontram, com menores dimensões se comparadas a jardins. Têm a função de receber, reter e infiltrar água de chuva; Biovaletas - trabalho no relevo do local de forma que as águas pluviais sejam conduzidas a uma valeta permeável, que desembocará em alguma bacia de retenção, detenção ou corpo hídrico próximo; Pavimentos permeáveis - pisos preparados para infiltrar parte da chuva incidente sobre o mesmo; Ruas verdes e vielas - ruas com estrutura mais bem preparada em termos de arborização e ajardinamento. Há a restrição de passagem de veículos motorizados; Estacionamentos verdes - espaços com pisos permeáveis ou superfície vegetada rasteira; Telhados verdes - estruturas que recebem espaços ajardinados sobre os telhados de uma construção; Arborização urbana - inserção e enriquecimento de espécies arbóreas no trecho urbano de uma cidade. 
Além destes, Herzog (2013) cita os alagados construídos (áreas que recebem águas geralmente poluídas ou com poluição difusa), bioengenharia (ou engenharia leve trabalhos de movimentação de solo, como taludes em beira de estrada, que visam benefícios como uma menor erosão do solo), interseções viárias (áreas permeáveis geralmente ilhadas e com difícil acesso ao pedestre, mas que têm mínima função biológica), lagoas pluviais (ou bacias de retenção, ou biorretenção - recebem as águas da chuva), lagoas secas (ou bacias de detenção - alguns parques são projetados para receber um grande volume de chuva e guardar temporariamente essas águas, infiltrandoas. Depois, as mesmas áreas podem ser aproveitadas para outros fins, como lazer ou prática de esportes), woonerf (ruas internas com circulação apenas de ciclistas e pedestres), vias de uso múltiplo (onde prega-se uma convivência pacífica entre os veículos não motores (bicicletas) e os demais motorizados) e corredores verdes (com a prioridade à instalação de espécies arbóreas e outras vegetais que garantam um fluxo gênico de fauna e flora). Smaniotto Costa (2012) relaciona, ainda, a ocorrência de uma modalidade de infraestrutura verde - os Kleingarten (espaços sub-utilizados, adotados pela população, transformados em hortas e jardins).

As tipologias citadas, formadoras do sistema de infraestrutura verde, apresentam um objetivo básico de mimetizar a natureza através de ecotécnicas que organizem o ambiente, diminuam impactos ambientais e garantam uma melhoria no meio urbano, quanto à umidade local, retenção de água, área de cobertura vegetal e maior fluxo de fauna e flora, dentre outros.

A retenção e infiltração de água trazidas por tais tipologias possibilita que o sub-solo seja recarregado e umedecido, devolvendo ao lençol freático e aos aquíferos locais parte da água retirada através da evaporação, evapotranspiração e consumos consuntivos da água superficial e subterrânea.

De acordo com Silveira (2001), o ciclo hidrológico é um processo no qual a água circula em sistema fechado entre a superfície terrestre e a atmosfera, impulsionada pela energia solar e associada pela gravidade terrestre. As gotas de água provenientes da chuva precipitação em forma líquida e fenômeno natural integrante do ciclo da água - podem causar impactos ao tocar a superfície terrestre. Quanto maior a cobertura vegetal desta superfície, menor será a enxurrada provocada, as enchentes, a erosão do solo e maior será o nível do lençol freático local (BERTONI \& LOMBARDI NETO, 2008).

Embora muitas cidades tenham suprimido diversas nascentes e córregos através de canalizações, tamponamentos e outras intervenções (BARTALINI, 2009), os principais cursos d'água e a topografia remanescente traçam as bacias hidrográficas lá existentes. Os estudos que associam o ciclo hidrológico (ou uma fase dele) e seus efeitos na superfície terrestre, são melhor desenvolvidos se adotados tendo a bacia hidrográfica como unidade de área. Isto porque a água que precipita nesta bacia, deverá infiltrar, evaporar ou escorrer superficialmente até que atinja o corpo d'água mais próximo.

Portanto, havendo áreas permeáveis, a água precipitada será retida em maior volume na bacia hidrográfica. Silveira (2001) conceitua bacia hidrográfica como sendo:

"uma área de captação natural da água de precipitação que faz convergir o escoamento para um único ponto de saída. A bacia hidrográfica compõe-se de um conjunto de superficies vertentes e de uma rede de drenagem formada por cursos de água que confluem até resultar em um leito único no seu exutório". 
A escala a ser adotada em um estudo pode variar desde $0,5 \mathrm{~km}^{2}$ de uma bacia localizada em área urbana, até $600.000 \mathrm{~km}^{2}$, que é a área aproximada da bacia do Rio São Francisco (PORTO \& PORTO, 2008).

Foi o objetivo, no presente artigo, o diagnóstico das áreas públicas institucionais e de recreio situadas na microbacia do Tijuco Preto em São Carlos (SP) e a possível aplicação de alguns elementos de infraestrutura verde nestes trechos públicos urbanos. A razão da escolha de áreas públicas deve-se à possibilidade de acesso aos locais para análise, à disponibilidade de dados e informações mais consistentes e à potencial melhoria destes espaços comuns, geralmente deficientes de tais ecotécnicas.

\section{MÉTODO}

A área adotada para estudo localiza-se no município de São Carlos (interior do Estado de São Paulo), mais precisamente em sua área urbana. Trata-se de uma microbacia hidrográfica (Tijuco Preto).

De acordo com o Instituto Brasileiro de Geografia e Estatística (2013), o município de São Carlos tem aproximadamente 221.000 habitantes em uma área de $1.137 \mathrm{~km}^{2}$, sendo que a área urbana ocupa $80,47 \mathrm{~km}^{2}$ (ou $7 \%$ da área total). Seus limites geográficos estão

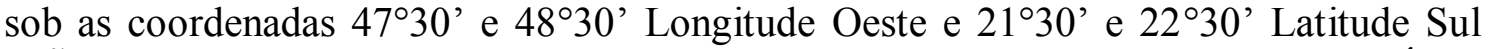
(SÃO CARLOS, 2013). O município conta com dois distritos - Santa Eudóxia e Água Vermelha - que podem ser observados na Figura 1, um pouco acima da delimitação da área urbana de São Carlos. No entanto, estes dois últimos não serão tratados no presente artigo.

A nascente do córrego do Tijuco Preto aflora a uma altitude de 846 metros acima do nível do mar e apresenta sua foz após 2.900 metros, desaguando no Ribeirão do Monjolinho, o corpo hídrico mais importante de São Carlos. A cidade foi fundada em 1850. No entanto, a ocupação regularizada do entorno do córrego do Tijuco Preto teve início na década de 40. Nas décadas de 80 e 90 houve uma segunda expansão no entorno do córrego (PAVEZZI NETTO et al, 2013). A Figura1 contextualiza a área de estudo. 
Figura 1- Área de estudo de caso, com destaque (em azul), no sentido horário, para: o Estado de São Paulo; o município de São Carlos; a área urbana de São

Carlos; a bacia hidrográfica do Tijuco Preto e; a mesma bacia e suas áreas públicas

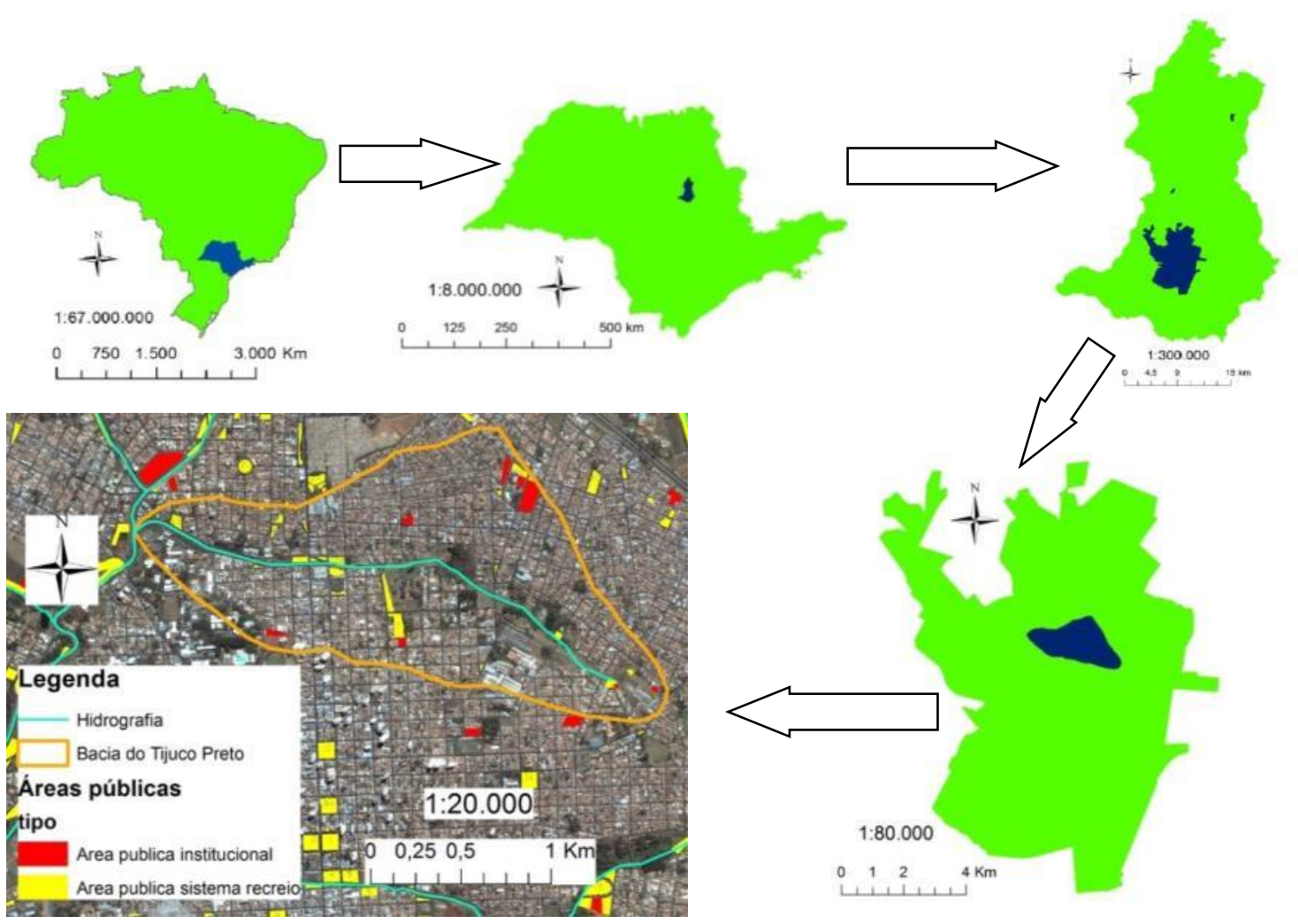

Fonte: Elaboração própria

A Economia do município é baseada predominantemente em Serviços (64,23\%), Indústria (33,37\%) e Agropecuária (2,4\%), com um PIB de R \$ 4.436.702.000 (IBGE, 2013).

De acordo com o Centro de Pesquisas Meteorológicas e Climáticas Aplicadas a Agricultura - CEPAGRI (2013), o clima do município de São Carlos é do tipo Cwa, considerando a classificação climática de Koppen (clima tropical de altitude), havendo duas estações definidas, sendo uma de 6 meses de verão chuvoso e outra com 6 meses de inverno seco. A temperatura média do mês mais quente é superior a $22^{\circ} \mathrm{C}$. A vegetação remanescente é predominantemente de cerrado.

Com um enfoque exploratório e descritivo, foi delineada uma metodologia baseada em pesquisa na literatura técnico-científica (bibliotecas e internet), além do levantamento de informações com o poder público local, que cedeu o mapeamento das áreas públicas institucionais e de recreio.

Recorreu-se à aplicação de Sistema de Informações Geográficas (SIG), com emprego de imagens de satélite Quick Bird, datadas de 2008 e com resolução espacial de 0,60 m, cedidas pelo Serviço Autônomo de Água e Esgoto de São Carlos (SC). O software utilizado (ArcGis 10.1) permitiu uma visualização geral e ampla, garantindo um exercício de projeção e aplicação de elementos de infraestrutura verde no objeto de estudo. Como auxílio, foram tiradas fotos in loco de cada trecho estudado, 
possibilitando uma visualização recente e mais detalhada de cada área, bem como um diagnóstico geral quali-quantitativo.

As camadas que relacionam a hidrografia, as áreas públicas do trecho urbano e demais informações técnicas do município, foram cedidas pela Secretaria de Habitação do governo municipal. Toda a base de dados foi trabalhada sob o Sistema de Coordenadas Planas SIRGAS 2000, Projeção Tranverse Mercator 23S.

$\mathrm{Na}$ parte introdutória deste artigo, foram relacionados diversos elementos formadores do sistema de infraestrutura verde nas áreas urbanas. No entanto, somente os seguintes serão considerados na avaliação das áreas para o presente artigo: desconexão de calhas, (DC); coleta de águas pluviais (CA); jardins de chuva (JC); biovaletas (BV); pavimentos permeáveis (PP); estacionamentos verdes (EV); telhados verdes (TV); arborização urbana (AU). Não serão considerados como candidatos à implementação (ou melhoria) as seguintes tipologias: Kleingarten, ruas verdes e vielas, bioengenharia, corredores verdes, vias de múltiplo uso, woonerf, lagoas secas, conservação da terra, lagoas pluviais e alagados construídos. Isso porque as áreas analisadas são trechos urbanos já ocupados e consolidados, com jardinamento ou construções. E os elementos excluídos são passíveis de aplicação somente em áreas abandonadas, vias trafegáveis ou terrenos mais amplos que exijam certa movimentação de terra.

\section{RESULTADOS E DISCUSSÃO}

A seguir são apresentadas, de forma sintetizada, as áreas públicas analisadas, suas características básicas e a sugestão de implementação ou melhoria dos elementos de infraestrutura verde selecionados. Após cada breve caracterização há, ao final, a sigla dos elementos que os autores sugerem implementar, a saber: DC (desconexão de calhas), CA (coleta de águas pluviais), JC (jardins de chuva), BV (biovaletas), PP (pavimentos permeáveis), EV (estacionamentos verdes), TV (telhados verdes) e AU (arborização urbana);

\section{1 Áreas públicas de recreio localizadas na micro-bacia do Tijuco Preto e sugestão de melhorias:}

- Praça Culto à Ciência - Área de $3.491 \mathrm{~m}^{2}$. Relativamente bem arborizada, apresenta calçada impermeável em todo seu entorno, além de caminhos e espaço, no interior, também impermeáveis. (JC; PP);

- Praça das Avencas - Área de $1.457 \mathrm{~m}^{2}$. Parcialmente tomada por uma quadra de bocha, esta praça apresenta mudas arbóreas em formação. Grama plantada e caminhos de passeio concretados. Há bancos de madeira, como equipamentos. Nenhum atrativo. (DC; CA; JC; PP; TV);

- Praça Tomaz Casale - Área de $1.124 \mathrm{~m}^{2}$. Relativamente bem arborizada, esta área possui caminhos e calçadas impermeáveis. Nenhum equipamento ou atrativo presente. (JC; PP);

- Praça Duque de Caxias - Área de $577 \mathrm{~m}^{2}$. Relativamente arborizada, com calçamento e caminhos impermeáveis. Apresenta alguns bancos de cimento, dois telefones públicos e abriga um ponto de ônibus. (JC; PP);

- Praça General Carlos de Meira Matos - Área de $2.931 \mathrm{~m}^{2}$, em frente à rodoviária. A praça é bem arborizada, com calçamento impermeável circundando-a. Junto a esta área 
há mais três espaços públicos voltados a recreio, que somam $6.380,7 \mathrm{~m}^{2}$. Estes apresentam árvores em formação e caminhos impermeáveis de cimento. (JC; PP)

- Praça Paulo Apolinário de Oliveira - Área de $504 \mathrm{~m}^{2}$. Espaço permeável, no entanto, sem qualquer atrativo ou equipamento instalado. (JC; PP; AU);

- Praça 2 de julho - Área de $2.905 \mathrm{~m}^{2}$. Há um pequeno playground instalado e mudas de árvore em formação. Parte existente da calçada é impermeável. Abriga um ponto de ônibus. (JC; PP);

- Praça Arnold Schimidt - Área de $1.006 \mathrm{~m}^{2}$. Neste espaço há um prédio da prefeitura e, ao lado, uma pequena praça arborizada apenas em uma lateral que tem sido usada como estacionamento de automóveis. Apresenta calçada impermeável em sua extensão. (DC; CA; JC; PP; TV; AU);

- Praça Guerino Deriggi - Área de $197 \mathrm{~m}^{2}$. Espaço pequeno, triangular, fruto de uma bifurcação viária. Há três bancos de madeira e 1 árvore adulta, suficiente para a cobertura da praça. Apresenta calçada impermeável em seu entorno. (JC; PP);

- Praça Sebastião Bataglia - Área de 485,6 m². Praça relativamente arborizada com presença de substancial área interna impermeável, além das calçadas. (JC; PP);

- Praça Estanislau Kruzeynski - Área de $347,5 \mathrm{~m}^{2}$. Praça relativamente arborizada, com mudas de árvore em formação e boa parcela interna, além da calçada do perímetro, impermeabilizando o solo. (JC; PP);

- Praça Delmas Penteado Machado - Área de $7.219 \mathrm{~m}^{2}$. Das áreas observadas, esta é a mais bem conservada de todas em termos de cobertura arbórea, sem caminhos internos impermeáveis. Apresenta duas entradas com pouca possibilidade de desfrute da população, dada sua localização e seu perímetro quase todo cercado. As calçadas próximas são cimentadas. (PP);

- Praça Paul Percy Harris - Área de $481 \mathrm{~m}^{2}$. Espaço relativamente arborizado. Apresenta calçamento impermeável em seu perímetro. (JC; PP);

\section{2 Áreas públicas institucionais localizadas na micro-bacia do Tijuco Preto e sugestão de melhorias:}

- CEMEI "Prof. Julien Fauvel" - Área de $2.222 \mathrm{~m}^{2}$. Área bem arborizada, no entanto, com calçadas impermeáveis e parcialmente deformadas por conta do sistema radicular das árvores. (DC; CA; JC; PP; TV);

- Corpo de Bombeiros - Área de $4.399 \mathrm{~m}^{2}$. Terreno usado para o estacionamento de viaturas e treinamento de pessoal. As calçadas que contornam o posto são impermeáveis. (DC; CA; JC; PP; EV; TV);

- Unidade Básica de Saúde Dr. Luiz Valente de Oliveira - Área de $2.273 \mathrm{~m}^{2}$. Apresenta uma pequena área permeável e calçadas impermeáveis. (DC; CA; JC; PP; TV);

- Escola Municipal de Educação Infantil "Helena Gornfeld" - Área de $12.694 \mathrm{~m}^{2}$. O terreno delimitado como institucional abriga, ainda, um campo de futebol e uma quadra poliesportiva coberta. A área referente à escola apresenta espaços permeáveis e arborizados. As calçadas externas são impermeáveis. (PP; TV);

- Terreno cercado não identificado - Área de $2.199 \mathrm{~m}^{2}$. Espaço com boa cobertura arbórea. No entanto, as calçadas ao longo do terreno são impermeáveis. (PP); 
- CEMEI “Aracy Leite Pereira Lopes” - Área de $3.075 \mathrm{~m}^{2}$. Apresenta horta, é relativamente arborizada. $\mathrm{O}$ solo é permeável, mas não apresenta cobertura vegetal. As calçadas são impermeáveis. (DC; CA; JC; PP; TV; AU);

- Praça superior à Rodoviária - Área de $882 \mathrm{~m}^{2}$. Espaço arborizado e ajardinado. Apresenta pisos e caminhos impermeáveis. (JC; PP);

- Seis terrenos vazios, sem construção ou equipamentos - Somam 10.111,7 m². São geralmente terrenos mais afastados do passeio de pedestres, localizando-se próximos ao Córrego do Tijuco Preto. (JC);

Através da descrição apresentada algumas características das áreas estudadas podem ser inferidas. Todas elas são passíveis da aplicação de algum elemento de infraestrutura verde dentre os selecionados. A desconexão de calhas e a coleta de águas pluviais podem ocorrer em todas as áreas que contem construções e telhado, geralmente as áreas institucionais. No entanto, a existência de uma, anula a possibilidade da ocorrência da outra. Já os telhados verdes podem ser instalados concomitantemente. Embora seja um elemento bastante importante, a biovaleta não se aplicou em nenhum caso, por não se tratar de área pública grande onde a água proveniente da chuva possa convergir e ser "canalizada" até algum corpo hídrico. A implementação de estacionamento verde é sugerida no pátio do corpo de bombeiros. A arborização urbana, embora presente na maioria das áreas analisadas, poderia receber maiores cuidados como podas corretivas, de limpeza e manejo das raízes além da seleção acertada de espécies arbóreas para calçadas e outras áreas estratégicas. Os jardins de chuva (ou canteiros pluviais, quando em áreas menores) são passíveis de implementação em praticamente todos os terrenos, uma vez que consistem em uma simples adaptação de rebaixamento das áreas aptas à recepção e infiltração das águas pluviais. Por fim, os pavimentos permeáveis poderiam ser aplicados em praticamente todas as áreas analisadas. Estas contam com pisos cimentados em seu entorno e outras apresentam caminhos impermeabilizados no interior de seus espaços, dificultando a infiltração das águas. Sabe-se que a impermeabilização de pisos e caminhos é empregada visando menores custos de manutenção. No entanto, quando bem implementados, os pisos permeáveis trazem vantagens ambientais e estéticas, além de serem eficazes em seus papéis. As Figuras 2 e 3 apresentam áreas de recreio e institucionais, respectivamente, para ilustrar a demanda aventada.

\section{Figura 2 - Áreas públicas de recreio. Praça Apolinário de Oliveira (a) e Praça Percy Harris (b)}
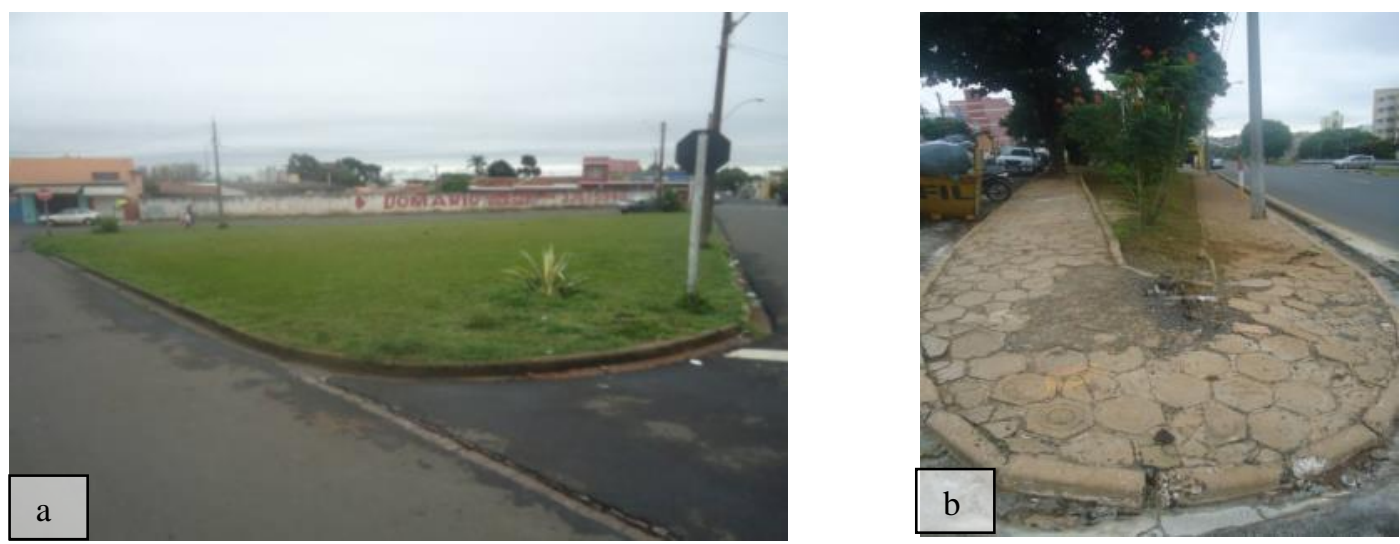

Fonte: Fotos tiradas pelos autores 


\section{Figura 3 - Áreas públicas institucionais. Unidade Básica de Saúde Dr. Luiz Valente de Oliveira (a) e Corpo de Bombeiros (b)}
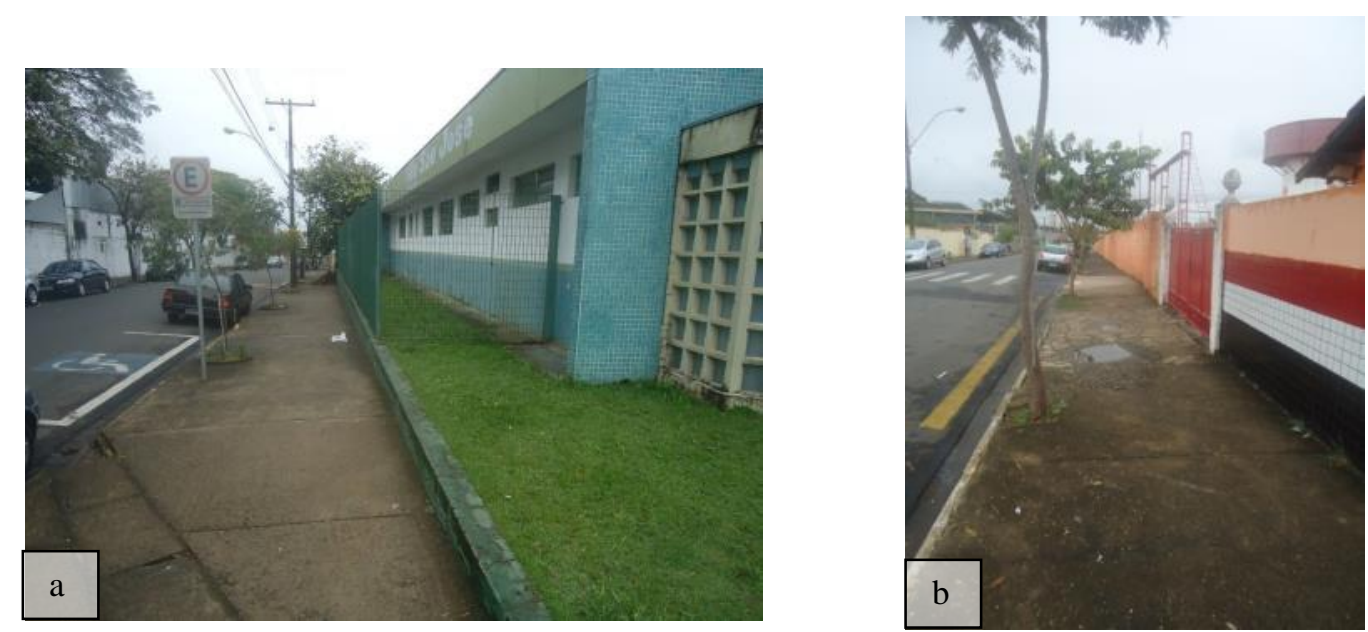

Fonte: Fotos tiradas pelos autores

A questão da implementação destes elementos de infraestrutura verde passa pela organização do poder público em seus espaços ajardinados. Também é importante a consciência da população em demandar tais características nas áreas públicas de sua cidade. No entanto, estas ações devem depender antes do conhecimento de tais elementos, seus benefícios e vantagens por parte do poder público e do cidadão comum. Ações de educação ambiental podem ser um bom começo para a conscientização da importância dos espaços públicos e o papel ambiental que áreas, mesmo reduzidas, podem conferir à região.

\section{CONSIDERAÇÕES FINAIS}

Pôde ser observado que as áreas públicas estudadas da micro-bacia do Tijuco Preto são passíveis de melhorias nos diversos aspectos levantados. Os pavimentos permeáveis e os jardins de chuva foram aqueles que apresentariam contribuição em praticamente todos os espaços analisados. Outros elementos não menos importantes como a instalação de telhados verdes, desconexão de calhas ou coleta de águas pluviais, poderiam ser aplicados em construções localizadas predominantemente nas áreas institucionais, com função de maior aproveitamento das águas pluviais. Em menor destaque apareceram os estacionamentos verdes e biovaletas. A arborização urbana, embora presente, poderia ser melhorada em diversos aspectos, a começar pela seleção correta de espécies para calçadas. Podas corretivas e de manutenção executadas de forma incorretas também foram observadas, fazendo crer que a reciclagem (com cursos) de trabalhadores que cuidam dos jardins é uma questão necessária e estratégica. No entanto, nenhuma aplicação ou melhoria dos elementos citados neste artigo será eficaz se não houver antes uma conscientização coletiva dos benefícios ambientais, sociais e econômicos oferecidos pelos elementos de infraestrutura verde. 


\section{REFERÊNCIAS}

BARTALINI, V. Os córregos ocultos e a rede de espaços públicos urbanos. Arquitextos. Mar. 2009. Disponível em: < http://www.vitruvius.com.br/revistas/read/arquitextos/09.106/64>. Acesso em: 4 abr. 2014.

BERTONI, J.; LOMBARDI NETO, F. Conservação do solo. 6.ed. São Paulo: Ícone. 355p. 2008.

CENTRO DE PESQUISAS METEOROLÓGICAS E CLIMÁTICAS APLICADAS A AGRICULTURA. Clima dos municípios paulistas. 2013. Disponível em: <http://www.cpa.unicamp.br/outras-informacoes/clima-dos-municipios-paulistas.html>. Acesso em: 2 abr. 2014.

ENVIRONMENTAL PROTECTION AGENCY. Green Infrastructure. 2013. Disponível em: $<$ http://water.epa.gov/infrastructure/greeninfrastructure/index.cfm\#Principles_of_Green_Infrastr ucture> Acesso em: 4 abr. 2014.

HERZOG, C. P. Cidades para todos: (re) aprendendo a conviver com a natureza. 1 ed. Rio de Janeiro: Mauad X: Inverde, p.312, 2013.

INSTITUTO BRASILEIRO DE GEOGRAFIA E ESTATÍSTICA. IBGE Cidades. Dados básicos de São Carlos/SP. $2013 . \quad$ Disponível em:< http://www.ibge.gov.br/cidadesat/painel/painel.php?codmun=354890\#>. Acesso em: 4 abr. 2014.

PAVEZZI NETTO, M., SCARPINELLA, G.D.A., SILVA, R. S. Environmental Analysis of Springs in Urban Areas - A Methodological Proposal. World Academy of Science, Engineering and Technology (Online), v. 76, p. 78-82, 2013.

PORTO, M. F. A., PORTO, R. L. Gestão de bacias hidrográficas. In: DOSSIÊE água: estudos avançados, v.22, n.63, p.43-60, maio/ago, 2008.

SÃO CARLOS. Lei $\mathbf{n}^{\mathbf{0}}$ 13.691/05. Plano Diretor de São Carlos Anexo 12 - Glossário. Disponível em: < http://www.saocarlos.sp.gov.br/index.php/utilidade-publica/planodiretor.html>. Acesso em: 4 abr. 2014.

SÃO CARLOS. Dados da cidade (Geográfico e demográfico), 2013. Disponível em :< http://www.saocarlos.sp.gov.br/index.php/conheca-sao-carlos/115442-dados-da-cidadegeografico-e-demografico.html>. Acesso em: 4 abr. 2013.

SILVEIRA, A. L. L. Ciclo hidrológico e a bacia hidrográfica. In: TUCCI, C.E.M. (Org.). Hidrologia: ciência e aplicação. 2.ed. Porto Alegre: Universidade UFRGS. Cap.2, p.35-51, 2001.

SMANIOTTO COSTA, C. Kleingärten - um componente da infraestrutura urbana: aspectos urbanísticos, ecológicos e sociais dos jardins arrendados na Alemanha. Revista Brasileira de Gestão Urbana. v.4, n.1, p.103-122, jan/jun, 2012.

Processo no 2014/16362-1, Fundação de Amparo à Pesquisa do Estado de São Paulo (FAPESP), pelo apoio na divulgação da pesquisa. 